\title{
Optimal Location of Upfc to Improve Power System Voltage Stability Using Artificial Bee Colony Algorithm
}

\author{
Bairu Vijay Kumar \\ Department of Electrical and Electronics Engineering, Kakatiya Institute of Technology and Science, Warangal, India
}

\section{Email address:}

bairuvijaykumar@gmail.com

\section{To cite this article:}

Bairu Vijay Kumar. Optimal Location of Upfc to Improve Power System Voltage Stability Using Artificial Bee Colony Algorithm. American Journal of Electrical Power and Energy Systems. Vol. 8, No. 2, 2019, pp. 42-49. doi: 10.11648/j.epes.20190802.11

Received: January 17, 2019; Accepted: March 7, 2019; Published: April 9, 2019

\begin{abstract}
In this paper a heuristic technique based optimal location of UPFC to improve the performance of power system is proposed. Here, the maximum power loss bus is identified as the most suitable location for fixing the UPFC. Generator outage affects the power flow constraints such as power loss, voltage, real and reactive power flow. Generator outage at different buses is introduced and the performance of the system is analyzed. The optimum location has been determined using the Artificial Bee Colony Algorithm (ABC) under this condition. By connecting UPFC at optimal location given by ABC algorithm, the power loss in the system is reduced and voltage profile is improved. Proposed work is implemented in the MATLAB and tested on IEEE 30 bus system. Initially the single generator outage is introduced at different buses in the system and afterwards double generator outage is introduced. In these conditions, the voltage profile and the power loss is analyzed at normal condition, outage condition and after connecting UPFC whose location given by proposed ABC algorithm. Performance of this algorithm is evaluated by comparing the results with those of different techniques. The comparison results demonstrate the superiority of the proposed approach and confirm its potential to solve the voltage stability problem.
\end{abstract}

Keywords: UPFC, ABC Algorithm, Power Loss, Generator

\section{Introduction}

The mount of electric power that can be transferred between two points through a transmission network is restricted by safety and stability constraints [1]. Around the world, Electric power systems have been forced to work more or less with their full capacities owing to the environmental and economic constraints in order to erect new generating plants and transmission lines [2-3]. Power flow in the lines should not be permitted to raise to a level where a random incident could cause the network fall down as a result of cascaded outages [4]. There have been many failures in the power system throughout the world due to voltage instability because of increasing system loads without sufficient transmission and/or generation enhancements [5]. When the voltages at the system buses are low, the losses will also be increased.

For controlling the power transmission system, Flexible AC Transmission System (FACTS) is a stationary tool that is employed in order to mitigate the above problems [6]. FACTS devices are basically power electronic devices that have the capability to control various parameters of transmission lines, both in steady-state and in dynamic state [7]. Various kinds of FACTS devices offered for this specific purpose involves Static Var Compensator (SVC), Thyristor controlled series Capacitor (TCSC), Static Synchronous series compensator (SSSC), Static Synchronous Compensator (STATCOM), Unified Power Flow Controller (UPFC) and Interline Power Flow Controller (IPFC) [9]. UPFC was one of the FACTS device proposed by L. Gyugyiand it is a multiple-functional FACTS device with primary duty of power flow control. The secondary functions of the UPFC can be voltage control, transient stability improvement and power oscillation damping etc. $[8,10]$.

Novel opportunities for controlling power and improving the utilizable sizing of surviving transmission lines are released by the appearance of FACTS devices [11]. An optimal location of UPFC permits to control its power flows for a meshed network and as a result the system load ability can be raised [12]. However, a limited number of devices, beyond which this load ability cannot be improved, are observed [13]. Due to high capital investment, it is necessary 
to locate FACTS devices optimally in the power system.

The optimal locationof FACTS in a power system is a problem ofcomplex mathematical analysis $[14,15]$. To solve this type of problem, different types of optimization algorithm have been used such as genetic algorithms, simulated annealing, tabu search and etc [16-17].

In this paper a heuristic technique based optimal location of UPFC to improve the power system voltage stability is proposed. Here, the maximum power loss bus is identified at the most favorable location for fixing the UPFC, because the generator outage affects the power flow constraints such as power loss, voltage, real and reactive power flow. The optimum location has been determined using the Artificial Bee Colony Algorithm (ABC). The rest of the paper organized as follows: the recent research works is analyzed in section 2; the proposed work brief explanation is explained in section 3; the suggested technique achievement results and the related discussions are given in section 4; and section 5 ends the paper.

\section{Recent Research Work: A Brief Review}

In literature, numbers of related works are available which based on improving the power transfer capability of power system. Some of them reviewed here.

Prabha Kunduret al. [18] defined and classified the power system stability in this paper. The problem of defining and classifying power system stability has been addressed by several earlier CIGRE and IEEE Task Force reports. This paper addresses the issue of stability definition and classification in power systems from fundamental view point and closely examines the practical ramifications.

M. J. Basleret al. [19] presented the basic concepts of Power System Stability and various types of Power System Stability. It covers the effects of system impedance and excitation on stability. Synchronizing torque and damping torque are discussed and justification is made for the need of supplemental stabilization.

GhamgeenIzat Rashed et al. [20] presented a Differential Evolutionary (DE)algorithm for finding the optimal location and the best parameter setting of Unified Power Flow Controller (UPFC) for minimizing the active and reactive power losses in the power system. Simulations have been implemented inMATLAB and the IEEE 14-bus and IEEE 30bus systems.

To get the optimal location of UPFCs for obtaining minimum total active and reactive power production cost of generators and minimizing the installation cost of UPFCs, the hybrid immune algorithm has been used by Seyed Abbas Taheret al. [21]. The UPFC is able to control voltage magnitude, voltage phase angle and impedance. As a result, it was employed successfully in this paper to increase power transfer capability of the existing power transmission lines and reduce operational and investment costs. They were executed simulations on IEEE 14-bus and 30-bus test system.
T. Nireekshanaet al. [22] have examined the exploit of FACTs tools, like SVC and TCSC, to take full advantage of power transfer transactions during normal and contingency conditions. To find out the location and control-ling parameters of SVC and TCSC, Real-coded Genetic Algorithm (RGA) was applied as an optimization tool. The proposed algorithm was experimented on IEEE 14-bus system and as well on IEEE 24-bus test system.

Using Fuzzy logic and Real Coded Genetic Algorithm, an approach for appointment and sizing of shunt FACTS controller has been suggested by A. R. Phadkeet al. [23]. A blurry presentation index based on distance to encumber node bifurcation, voltage profile and sizing of shunt FACTS controller is suggested. The suggested strategy has been used on IEEE 14-bus and IEEE 57-bus test systems.

K. Ravia et al. [24] have suggested an Improved Particle Swarm Optimization (IPSO) for optimizing the power system problems. For optimal sizing and distribution of a Static Compensator (STATCOM) and to reduce the voltage variations at all the buses in a power system, they used Improved Particle Swarm Optimization. This algorithm gets an optimal settings for current infrastructure with optimal locations, sizes and control settings for Static Compensator (STATCOM) units.

The heavy loading of lines, need to maintain constant bus voltages. Uncontrolled power exchanges are increasing in the power systems. For that reason, power systems need to be supervised. FACTS devices released positive latest prospects for controlling the power flow and expanding the load ability of the accessible power transmission system. Among the FACTS devices, the UPFC is one of the most promising FACTS devices for load flow control as it can concurrently control the active and reactive power flow in addition to the nodal voltages. As per the characteristics of the UPFC, scheduling the implementations, it has some practical concern for finding the optimal location. Several researches have effort to solve the optimal location of UPFCs with respect to different purposes and methods. For determining the optimal location, the operating condition of UPFC must be pre-assigned. Optimization algorithms are introduced to determine the location of UPFC such as genetic algorithm, particle swarm optimization, differential evaluation and etc. These methods did not succeed in determining optimal location for UPFC. The proposed method is briefly described in the following section.

\section{Problem Formulation}

\subsection{Power Flow Studies of UPFC}

The UPFC is one of the FACTS devices, which provides the independent control of the real and reactive power flow, voltage magnitude and enhance the dynamic stability of the system. The UPFC consists of two switching converters like series converter and shunt converter operated from a common DC link. The converters are connected to the power system via coupling transformers. The shunt converter is 
connected to the sending end node and the series converter is connected between the sending and receiving end. The series converter injects an AC voltage with controllable magnitude and phase angle in series with the transmission line. When the active power loss is neglected, the UPFC cannot generate or absorb the active power and the active power in the two converters must be balanced via the DC link. However the converters generate or absorb the reactive power and provide the independent shunt reactive compensation for the line. The UPFC structure can be described in the following Figure 1.

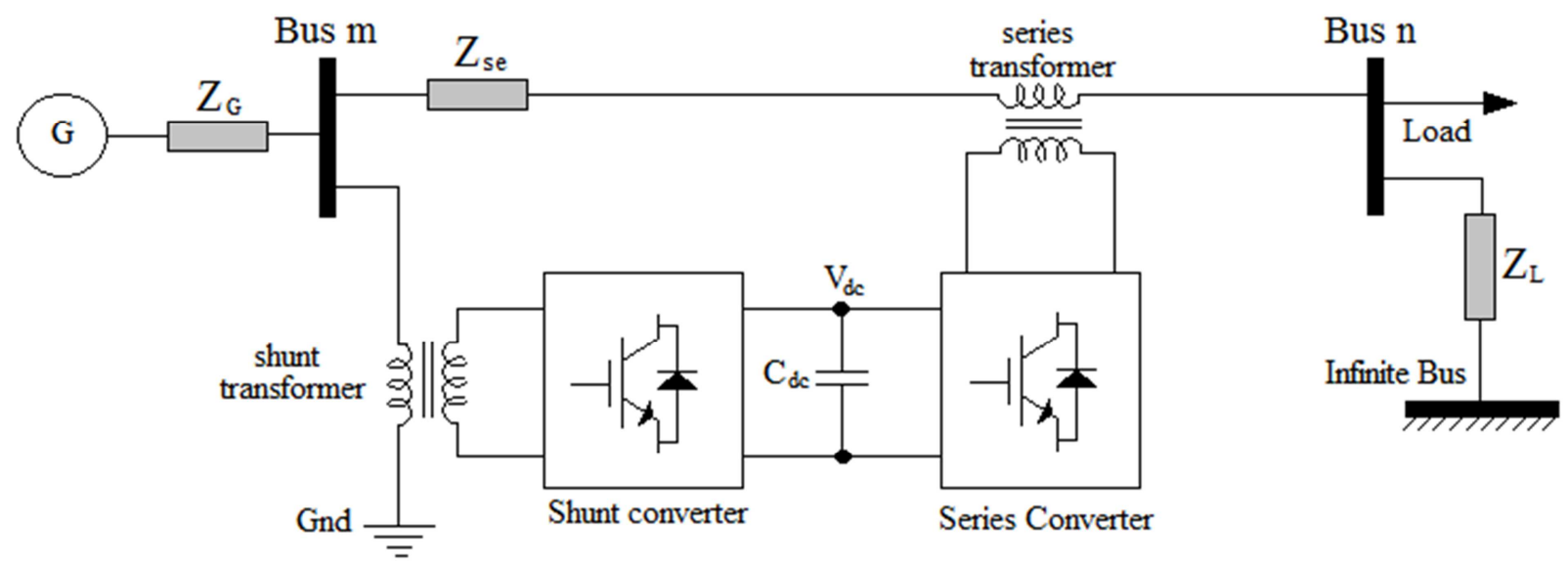

Figure 1. Structure of the UPFC.

The above Figure shows the structure of the UPFC; the Generator $G$ connected with the buses $m$ and $n$. Here the converters are connected via transformer. It includes the impedances of the converter such as series impedance $Z_{\text {se }}$, shunt impedance $Z_{s h}$, Generator side impedance $Z_{G}$ and load impedance $Z_{L}$. The converters are connected with the DC link capacitor $C_{d c}$ with voltage $V_{d c}$ capacity. These can be incorporated to the UPFC power flow equations [25]. The UPFC power flow equations are required to solve the power system affected quantities like equality constraints and the inequality constraints. It may occur due to the outage of generators presented in the power system, because the utilization side needs demand satisfaction at all the time. The disturbed quantities are briefly described in the following section.

\subsubsection{Equality Constraints}

The power system mainly contributes the satisfaction of total demand of the utilities. Here, the system generators must satisfy the total demand of the consumers as well as power loss of the transmission lines. It is denoted as the equality constraints or power balance condition of the power system. The generators presented in the system gets outage; it may increase the power loss and affects the dynamic stability environment. The required power balance condition can be described in the following equation (1).

$$
\sum_{i=1}^{N_{G}} P_{G}^{i}=P_{D}+\sum_{j=1}^{N_{G}}\left(P_{L}^{j}+j Q_{L}^{j}\right)
$$

Where, $P_{G}^{i}$ is the power generated in the $i^{t h}$ bus, $P_{D}$ is the demand, $P_{L}^{j}$ and $Q_{L}^{j}$ are the real and reactive power loss of the $j^{\text {th }}$ bus, The real and reactive power loss can be calculated in the following equations (2) and (3).

$$
\begin{aligned}
& P_{L}^{j}=\left|V_{i}\right|\left|V_{j}\right|\left|Y_{i j}\right| \sum_{n=1}^{N} \cos \left(\alpha_{i j}-\delta_{i}-\delta_{j}\right) \\
& Q_{L}^{j}=\left|V_{i}\right|\left|V_{j}\right|\left|Y_{i j}\right| \sum_{n=1}^{N} \sin \left(\alpha_{i j}-\delta_{i}-\delta_{j}\right)
\end{aligned}
$$

Where, $V_{i}$ and $V_{j}$ are the voltage of the buses $i$ and $j, Y_{i j}$ is the bus admittance matrix, $\alpha_{i j}$ is the angle between the buses $i$ and $j, \delta_{i}$ and $\delta_{j}$ are the load angle of $i$ and $j$. Similarly the inequality constraints are described in the following.

\subsubsection{Inequality Constraints}

This section describes the inequality constraints like voltage, real and reactive power flow. The mentioned factors are affected due to the generation unit's protest. These constraints are briefly explained in the following. The power system dynamic stability mainly considers the voltage stability of every node. The stable power flow needs the voltage at each bus at the range of 0.95 to $1.05 \mathrm{pu}$. The change in voltage can be described by the following equations (4).

$$
\Delta V_{i}=\frac{1}{\sqrt{l}} \sqrt{\sum_{i=1}^{l}\left(V_{i}^{k}\right)^{2}}
$$

Where,

$$
V_{i}^{k}=V_{\text {slack }}-\sum_{i=1}^{n} Z_{i}\left(\frac{P_{i}-j Q_{i}}{V_{i}}\right)
$$

With, $V_{\text {slack }}$ is the slack bus voltage, $\Delta V_{i}$ is the voltage stability index of the bus $i, V_{i}$ is voltage of the bus, where 
$i=1,2,3 \ldots n, Z_{i}$ is the impedance of the $i^{\text {th }}$ bus, $P_{i}$ and $Q_{i}$ are the real and reactive power of bus $i$ and $j$ is the number of nodes. The bus voltage lies between the limits, i.e., $V_{i}^{\min } \leq V_{i} \leq V_{i}^{\max }$. The real and reactive power of the particular bus can be described by the following equations (6) and (7).

$$
\begin{aligned}
& P_{i}=\left|V_{i}\right|\left|V_{j}\right| \sum_{n=1}^{N_{B}}\left(G_{i j} \cos \delta_{i j}+B_{i j} \sin \delta_{i j}\right) \\
& Q_{i}=\left|V_{i}\right|\left|V_{j}\right| \sum_{n=1}^{N_{B}}\left(G_{i j} \sin \delta_{i j}-B_{i j} \cos \delta_{i j}\right)
\end{aligned}
$$

Where, $V_{i}$ and $V_{j}$ are the voltage of $i$ and $j$ buses respectively, $N_{B}$ is the total number of buses, $\delta_{i j}$ and $\delta_{i j}$ are the angle between $i$ and $j$ buses respectively, $G_{i j}$ and $B_{i j}$ are the conductance and susceptance values respectively. Depending on these constraints, the optimum location and the UPFC has been determined using the proposed hybrid technique. It is briefly explained in the following section 3.2.

\subsection{Overview of the Proposed Technique}

In the paper optimal location of UPFC to improve power system stability based on a heuristic technique is proposed. Initially, the IEEE standard bench mark system's normal power flow and the stability condition are analyzed. Afterwards the generator outages are introduced in the system. Here, the maximum power loss bus is determined from the ABCalgorithm, it is identified as the most favorable location for fixing the UPFC. After connecting UPFC the systemis recoveredto the normal operating condition and stability is improved. The fundamentals of $\mathrm{ABC}$ algorithm is explained in section 3.2.1. The ABC algorithm based optimal location determination is explained in the section 3.2.2.

\subsubsection{Fundamentals of ABC Algorithm}

Several approaches have been proposed to model the specific intelligent behaviors of honey bee swarms. Artificial Bee Colony $(\mathrm{ABC})$ is a relatively new member of swarm intelligence. Karaboga has described the Artificial Bee Colony $(\mathrm{ABC})$ algorithm based on the foraging behavior of honey bees for numerical optimization problems. This Problem of optimization depends on a number of parameters and the choice of these parameters affects the performance.

In the Artificial Bee Colony (ABC) algorithm, the colony of artificial bees contains three groups of bees: employed bees, onlookers and scouts. A bee waiting on the dance area for making decision to choose a food source is called an onlooker and a bee going to the food source visited by it previously is named as employed bee. A bee carrying out random search is called a scout. In the $\mathrm{ABC}$ algorithm, first half of the colony consists of employed artificial bees and the second half constitutes the onlookers. For every food source, there is only one employed bee [26-27].

Short pseudo-code of the ABC algorithm is given below [26]:

1. Initialize the population of solutions

2. Evaluate the population

3. Produce new solutions for the employed bees

4. Apply the greedy selection process

5. Calculate the probability values

6. Produce the new solutions for the onlookers

7. Apply the greedy selection process

8. Determine the abandoned solution for the scout, and replace it with a new randomly produced solution

9. Memorize the best solution achieved so far

\subsubsection{ABC Based Optimum Location Determination}

In the proposed algorithm the optimum location of the UPFC is identified by UPFC. Here, the power flow terms such as voltage, real and reactive power flow and power loss are already determined using the Newton-Raphson (N-R) method. Then the generator outage is introduced at the generator buses, which causes the instability at the system. So the maximum power loss bus and the corresponding affecting parameters are obtained using the $\mathrm{ABC}$ algorithm. The algorithmic steps to optimize the location are given in the following.

Algorithm

Step1: Initialize the population of the line power loss and voltage $\left(X_{i}\right)$ at all the buses.

$$
X_{i}=\left[\left(V_{1}, P_{L 1}\right)^{B 1},\left(V_{2}, P_{L 2}\right)^{B 2},\left(V_{3}, P_{L 3}\right)^{B 3} \ldots\left(V_{n}, P_{L n}\right)^{B n}\right]
$$

Where, $\left(V_{1}, P_{L 1}\right)^{B 1}$ are the voltage and the power loss of the $B 1$ bus.

Step 2: Generate the random number of population input voltage and the power loss.

Step 3: The employ bee phase, which evaluates the fitness of the population; the required fitness function is given in the following equation (9).

$$
\Phi=\operatorname{Max}\left\{\left|V_{i}\right|\left|V_{j}\right|\left|Y_{i j}\right| \sum_{n=1}^{N} \cos \left(\alpha_{i j}-\delta_{i}-\delta_{j}\right)\right\}
$$

Step 4: Set the iteration count as 1 , i.e., iteration $\mathrm{I}=1$.

Step 5: Repeat

Step 6: The onlooker bee attains the elite fitness function of the bus system and improve the velocity of the populations using the following equation (10).

$$
V_{i, j}=x_{i, j}+\Phi_{i, j}\left(x_{i, j}-x_{k, j}\right)
$$

Where, $\mathrm{k}$ is the solution the neighborhood of $i, \Psi$ is a random number in the range $[-1,1], k=(1,2,3 \ldots n)$ and $j=(1,2,3 \ldots n)$ are the randomly chosen index and $V_{i, j}$ is the neighborhood solution of $X_{i}$.

Step 7: Apply the selection process to find the better fitness of the new solutions and determine the probability. 


$$
\text { probability }=\frac{\Phi}{\sum_{i=1}^{n} \Phi}
$$

Step 8: If better solutions are not achieved, abandon the solutions and produce the random number of scout bee solution using the following equation (12).

$$
x_{i}^{j}=x_{\min }^{j}+\operatorname{rand}[0,1]\left(x_{\max }^{j}-x_{\min }^{j}\right)
$$

Step 9: Memorize the best solution achieved so far.

Step 10: To check the iteration range, if the iteration not achieves the maximum range increase the iteration count $\mathrm{I}=\mathrm{I}+1$ or else terminate the process.

Once the above process is finished, the system is ready to produce the maximum power loss bus for the specified generator bus outage condition. Once the UPFC is connected at optimum location given by the algorithm, power loss is minimized, voltage profile is improved thus power system stability improved. The proposed algorithm is implemented in the MATLAB platform and its performance is checked with various operating conditions. It is given in the following section 4.

\section{Results and Discussions}

The proposed algorithm is implemented in the MATLAB platform. The numerical results of the proposed method is presented and discussed in this section. The obtained results are compared with various operating environments. Here, the $\mathrm{ABC}$ algorithm is applied to the IEEE standard bench mark system like IEEE 30 bus system.

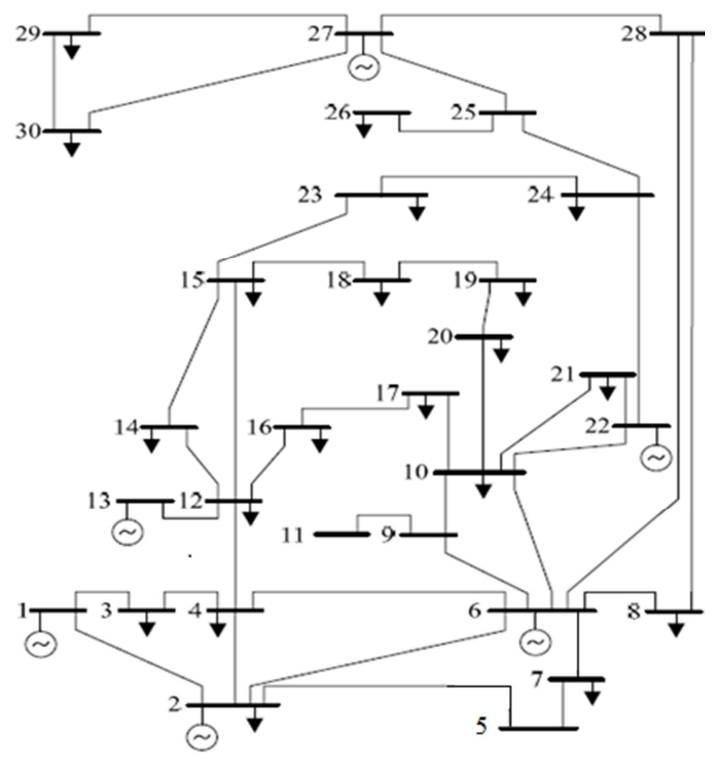

Figure 2. Structure of the IEEE 30 bus system.

Validation of IEEE 30 bus system

The Structure of the IEEE 30 bus system is shown in Figure 2. IEEE-30 bus benchmark system consists of six generator buses, 21 load buses and 42 transmission lines. Initially, the system base case load flow analysis is done by the standard Newton-Raphson (N-R) algorithm. Here, the IEEE 30 bus system standard data isused. Afterwards, the generator outages (single and double) are introduced and the corresponding stability is analyzed. Due to the generator outages the system loses the stability, which can be identified by the load flow analysis of the system after the generator outage. Stability conditions can be restored by connecting optimum sizing of UPFC placed at optimal location, which can be determined by the proposed ABC algorithm.

\subsection{Single Generator Outage}

In this case at a time one generator is given outage and corresponding stability is analyzed.

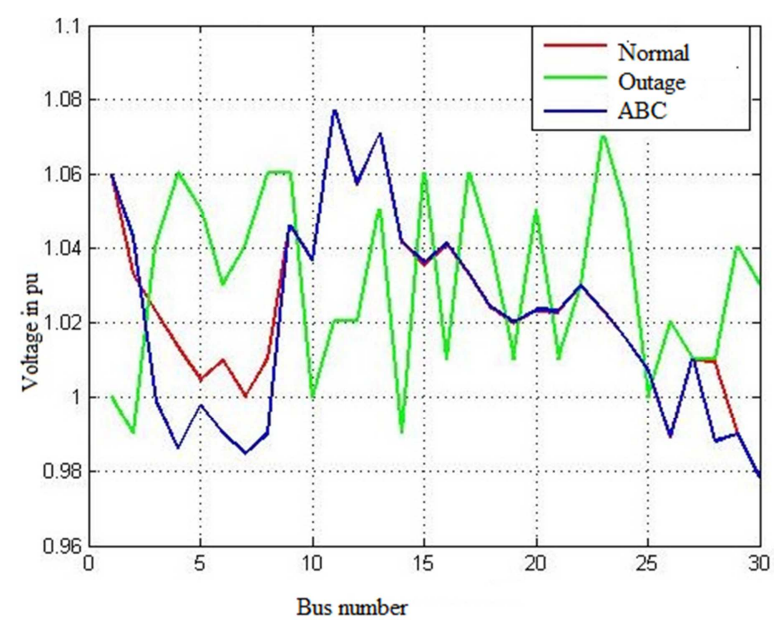

Figure 3. Voltage profile for $2^{\text {nd }}$ bus generator outage condition with $A B C$ algorithm.

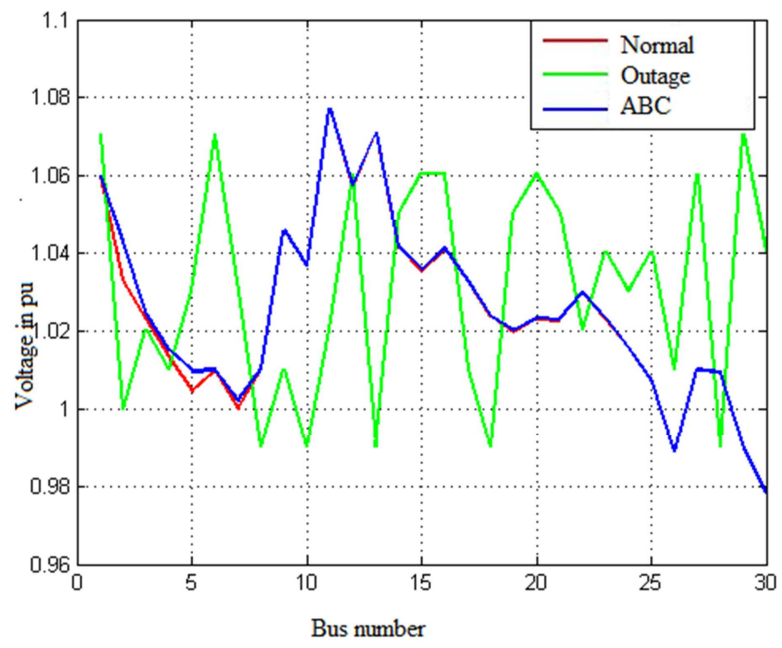

Figure 4. Voltage profile for $6^{\text {th }}$ bus generator outage conditionwith $A B C$ algorithm.

The voltage profile variation for IEEE-30 bus system at single generator outage is shown in Figure 3. Here, second bus generator is given outage. The voltage profile is shown for normal condition, during the generator outage and after connecting the UPFC whose location is determined using $\mathrm{ABC}$ algorithm. The voltage profile variations of the same system for sixth bus generator outages is shown in Figure 4. 
From the voltage profile analysis, it is found that the voltage profile is disturbed for the generator outage condition. But the voltage profile is restored to the normal condition after connecting UPFC.

Table 1. Power loss comparison for single generator outage condition using ABC algorithm.

\begin{tabular}{llll}
\hline $\begin{array}{l}\text { Outage of } \\
\text { generatorat bus no. }\end{array}$ & Power loss in MW & & \\
\cline { 2 - 4 } & During normal condition & During generator outage condition & $\begin{array}{l}\text { After connecting UPFC whose } \\
\text { location is given by ABC algorithm }\end{array}$ \\
\hline 2 & 10.809 & 12.768 & 9.858 \\
\hline
\end{tabular}

Table 1 gives power loss comparison for different conditions i.e. Power loss at normal condition, generator outage condition and after connecting the UPFC at optimal location which is determined using $\mathrm{ABC}$ algorithms. Here, it is observed that the power loss is increased to $12.768 \mathrm{MW}$ during single generator outage condition and the power loss is reduced to $9.858 \mathrm{MWafter}$ connecting UPFC whose location is determined by proposed $\mathrm{ABC}$ algorithm. This shows effectiveness of proposed algorithm.

\subsection{Double Generator Outage Condition}

In this case at a time two generators are given outages and corresponding stability is analyzed.

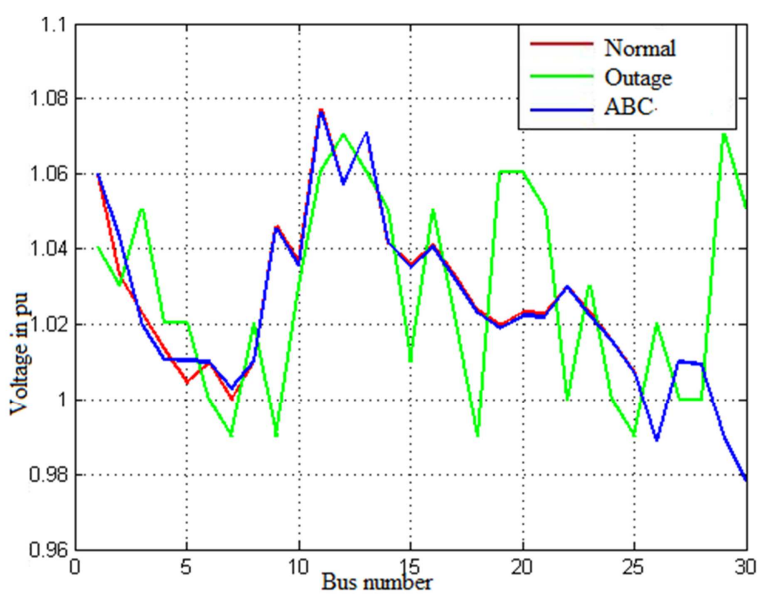

Figure 5. Voltage profile for generators outage at buses 2 and 6 with $A B C$ algorithm.

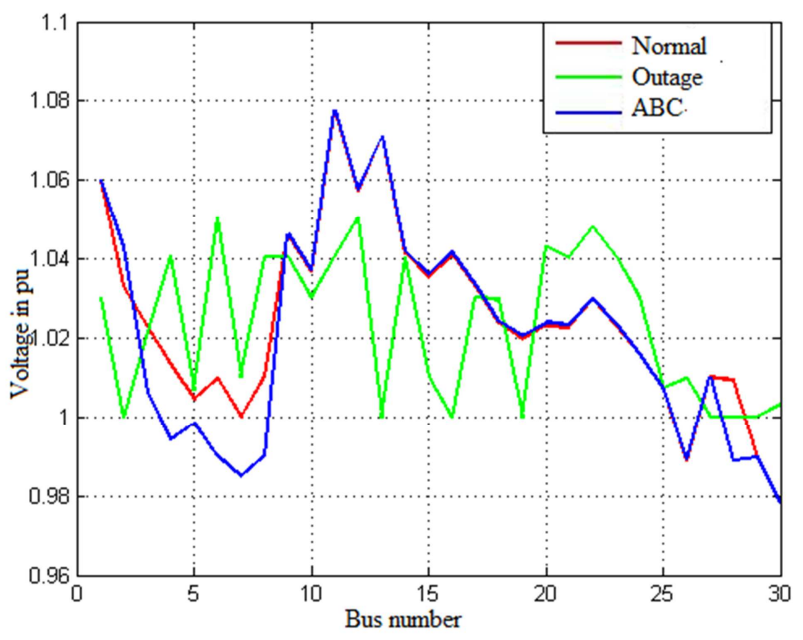

Figure 6. Voltage profile for generators outage at buses 2 and 13 with $A B C$ algorithm.
The voltage profile variation for IEEE-30 bus system at double generator outage is shown in Figure 5. Here generators at buses $2 \& 6$ are given outage. The voltage profile is shown for normal condition, during the double generator outage and after connecting the UPFC whose location is determined using $\mathrm{ABC}$ algorithm. Figure 6 shows voltage profile variations for double generator outage at buses $2 \& 13$. From the voltage profile analysis, it is found that the voltage profile at the buses is disturbed for the generator outage, but the voltage profile is restored to normal condition after connecting the UPFC. Table 2 gives power loss comparison under double generator outages for different conditions i.e. Power loss at normal condition, Power loss at double generator outage condition, Power loss after connecting the UPFC at optimal location which is determined using $\mathrm{ABC}$ algorithm. Here, it can be observed that power loss is increased to $14.005 \mathrm{MW}$ during double generator outage and it is reduced to $9.862 \mathrm{MW}$ after connecting UPFC whose location and sizing are given by proposed $\mathrm{ABC}$ algorithm. Figures 3 to 6 and Tables 1 to 2 clearly show the effectiveness and superiority of the proposed $\mathrm{ABC}$ algorithm to restore power system stability under generator outage conditions.

Table 2. Power loss comparison for double generator outage using Hybrid ABC-GSA algorithm.

\begin{tabular}{llll}
\hline \multirow{2}{*}{$\begin{array}{l}\text { Outage of generators } \\
\text { at bus nos. }\end{array}$} & \multicolumn{3}{l}{ Power loss in MW } \\
\cline { 2 - 4 } & $\begin{array}{l}\text { During normal } \\
\text { condition }\end{array}$ & $\begin{array}{l}\text { During generator } \\
\text { outage condition }\end{array}$ & ABC \\
\hline 6 & 10.809 & 14.005 & 9.862 \\
\hline
\end{tabular}

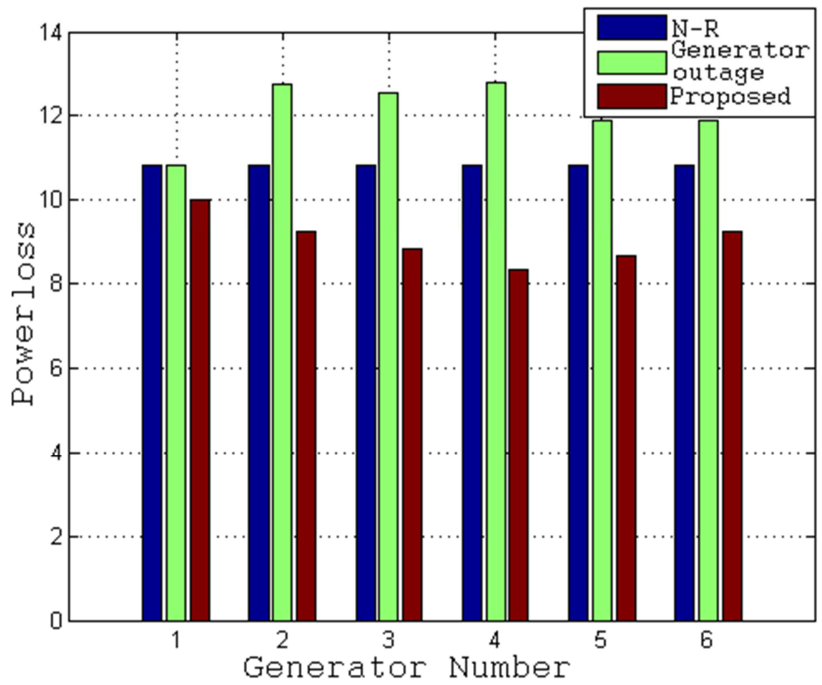

Figure 7. Power loss at single generatoroutage condition. 


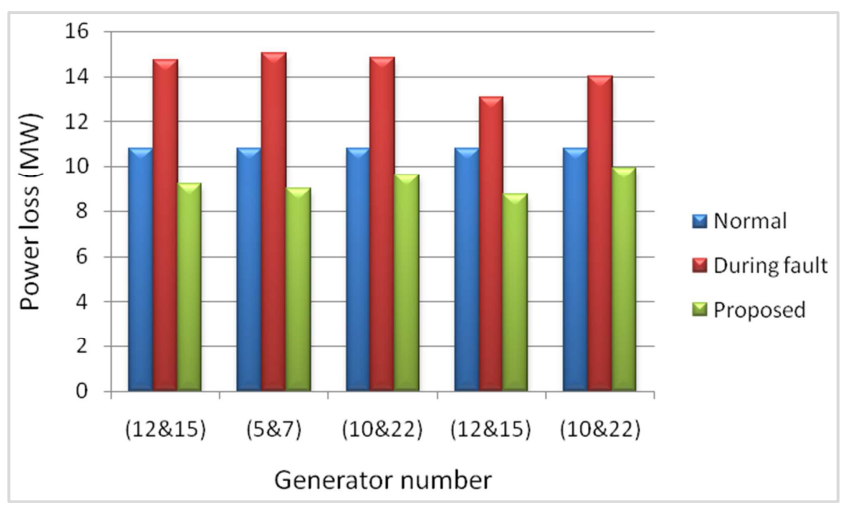

Figure 8. Power loss at double generators outage condition.

The power loss reduction using proposed method at single generator outage is shown in Figure 7 . Then the power loss reduction using proposed method at the double generatoroutage is shown in the Figure 8. These Figures show the proposed method has reduced power loss by connecting UPFC at optimum location given by the ABC algorithm.

\section{Conclusion}

In this paper, the effectiveness of the optimal location of UPFC to enhance the power system stability is proposed. Here, the proposed method was applied into the IEEE 30 bus bench mark system and the effectiveness is tested against different generator outages. Initially the single generator outage is performed at different buses in the system and afterwards double generator outage is introduced. In these conditions, the voltage profile and the power loss is analyzed at normal condition, outage condition and with proposed $\mathrm{ABC}$ algorithm. From the presented analysis, we concluded that, the proposed algorithm was effectively enhancing the stability of the system by giving optimum location of the UPFC, which is competent over the other techniques.

\section{References}

[1] P. Ramasubramanian, G. Uma Prasana, and K. Sumathi, "Optimal Location of FACTS Devices by EvolutionaryProgramming Based OPF in Deregulated Power Systems", British Journal of Mathematics \& Computer Science, Vol. 2, No. 1, pp. 21-30, 2012.

[2] Rakhmad Syafutra Lubis, Sasongko Pramono Hadi, and Tumiran, "Selection of Suitable Location of the FACTS Devices for Optimal Power Flow", International Journal of Electrical \& Computer Sciences, Vol. 12, No. 3, pp. 38-49, 2012.

[3] S. Durairaj, and B. Fox, "Optimal Placement of Facts Devices", International Conference on Energy \& Environment, 2008.

[4] D. Devaraj, and J. Preetha Roselyn, "Genetic algorithm based reactive power dispatch forvoltage stability improvement", International Journal of Electrical Power \& Energy Systems, Vol. 32, No. 10, pp. 1151-1156, December 2010.
[5] A. H. Khazali, and M. Kalantar, "Optimal reactive power dispatch based on harmony search algorithm", International Journal of Electrical Power \& Energy Systems, Vol. 33, No. 3, pp. 684-692, March 2011.

[6] Rahul J. Shimpi, Rajendra P. Desale, Kunal S. Patil, Jaswantsing L. Rajput and Shailesh B. Chavan, "Flexible AC Transmission Systems", International Journal of Computer Applications, Vol. 1, No. 15, pp. 54-57, 2010.

[7] H O Bansal, H P Agrawal, S Tiwana, A R Singal and L Shrivastava, "Optimal Location of FACT Devices to Control Reactive Power", International Journal of Engineering Science and Technology, Vol. 2, No. 6, pp. 1556-1560, 2010.

[8] D. Murali, and M. Rajaram, "Active and Reactive Power Flow Control using FACTS Devices", International Journal of Computer Applications, Vol. 9, No. 8, pp. 45-50, 2010.

[9] Xuan Wei, Joe H. Chow, Behruz Fardanesh and Abdel-Aty Edris, "A Common Modeling Framework of Voltage-Sourced Converters for Load Flow, Sensitivity, and Dispatch Analysis", IEEE Transactions On Power Systems, Vol. 19, No. 2, pp. 934-941, May 2004.

[10] S. V. Ravi Kumar, and S. Siva Nagaraju, "Functionality of UPFC in Stability Improvement", International Journal of Electrical and Power Engineering, Vol. 1, No. 3, pp. 339-348, 2007.

[11] Jigar S. Sarda, Vibha N. Parmar, Dhaval G. Patel, and Lalit K. Patel, "Genetic Algorithm Approach for Optimal location of FACTS devices to improve system loadability and minimization of losses", International Journal of Advanced Research in Electrical, Electronics and Instrumentation Engineering, Vol. 1, No. 3, pp. 114-125, 2012.

[12] Gerbex, S., Cherkaoui, R., and Germond, A. J., "Optimal location of FACTS devices to enhance power system security", IEEE Bologna Power Tech Conference Proceedings, 2003.

[13] Cai, L. J., Erlich, I., and Stamtsis, G., "Optimal choice and allocation of FACTS devices in deregulated electricity market using genetic algorithms", IEEE PES Power Systems Conference and Exposition, 2004.

[14] Wang Feng, and Shrestha, G. B., "Allocation of TCSC devices to optimize total transmission capacity in a competitive power market", IEEE Power Engineering Society Winter Meeting, 2001.

[15] Vaidya, P. S., and Rajderkar, V. P., "Optimal Location of Series FACTS Devices for Enhancing Power System Security", 4th International Conference on Emerging Trends in Engineering and Technology, 2011.

[16] Mori, H., and Goto, Y., "A parallel tabu search based method for determining optimal allocation of FACTS in power systems", International Conference on Power System Technology, 2000.

[17] Mahdad, B., Bouktir, T., and Srairi, K., "GA Coordinated with Practical Fuzzy Rules with Multi Shunt FACTS Devices to Enhance the Optimal Power Flow", The International Conference on Computer and Tool, 2007.

[18] Prabha Kundur, John Paserba, Venkat A, Goran Andersson, Anjan Bose, Claudio Canizares, Nikos Hatziargyriou, David hill, Alex stankovic, Carson Taylor, Thierry Van Custem and Vijay vital, " Definitions and Classification of power system stability", IEEE Transactions on power system , Vol. 19, No. 2, pp. 1387-1401, May 2004. 
[19] Basler, M. J. Schaefer, R. C. Understanding Power System Stability. IEEE Transactions on Industry Applications. March/April 2008; 44(2): 463-474.

[20] Ghamgeen Izat Rashed, Yuanzhang Sun, Khalid A. Rashed, and H. I. Shaheen, "Optimal Location of Unified Power Flow Controller by Differential Evolution Algorithm Considering Transmission Loss Reduction", IEEE POWECON 2012, pp16.

[21] Seyed Abbas Taher, and Muhammad KarimAmooshahi, "New approach for optimal UPFC placement using hybrid immunealgorithm in electric power systems", Electrical Power and Energy Systems, Vol. 43, pp. 899-909, 2012.

[22] T. Nireekshana, G. Kesava Rao, and S. Siva Naga Raju, "Enhancement of ATC with FACTS devices using Real-code Genetic Algorithm", Electrical Power and Energy Systems, Vol. 43, pp. 1276-1284, 2012.

[23] A. R. Phadke, and Manoj Fozdar, K. R. Niazi, "A new multiobjective fuzzy-GA formulation for optimal placement and sizing of shunt FACTS controller", International Journal of Electrical Power \& Energy Systems, Vol. 40, No. 1, pp. 46-53, September 2012.

[24] K. Ravia and M. Rajaram, "Optimal location of FACTS devices using Improved Particle Swarm Optimization", International Journal of Electrical Power \& Energy Systems, Vol. 49, pp. 333-338, July 2013.

[25] AbdelazizLaifa and Mohamed Boudour, "Optimal Placement and Parameter Settings of Unified Power Flow Controller
Device using a Perturbed Particle Swarm Optimization", IEEE International Energy Conference and Exhibition, pp. 205-210, 2010.

[26] D. Karboga and B. Basturk, "A Powerful and efficient algorithm for numerical function optimization: Artificial bee colony (ABC) algorithm", Applied Soft Computing, Vol. 8, No. 1, pp. 687-697, 2008.

[27] D. Karboga and Bahriye Akay, "A comparative study of Artificial Bee Colonyalgorithm", Applied Mathematics and Computation, Vol. 214, No. 1, pp. 108-132, 2009.

\section{Biography}

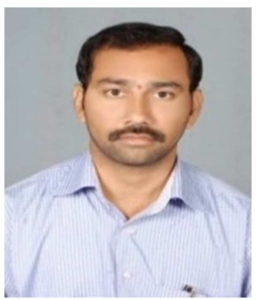

Bairu Vijay Kumar was born in Warangal, India, in April 1978. He received the B. Tech degree in Electrical \& Electronics Engineering, M. Tech degree in Power Systems Engineering and Ph.D in electrical engineering from National Institute of Technology, Warangal, India, in 2002, 2008 and 2015 respectively. He is currently working as Asst. professor in EEED of Kakatiya institute of Technology \&Science, Warangal, India. He published papers in various Sci indexed and other peer reviewed journals. His Current research interest includes Enhancement of Power System Stability using FACTS devices and AI techniques. 